\title{
Efficacy and safety of adjunctive anticoagulation in patients with lung cancer without indication for anticoagulants: a systematic review and meta-analysis
}

\author{
Jing Zhang, ${ }^{1}$ Yue-Li Zhang, ${ }^{2}$ Kai-Xiang Ma, ${ }^{3}$ Jie-Ming $\mathrm{Qu}^{2}$
}

\begin{abstract}
- Additional material is published online only. To view please visit the journal online (http://dx.doi.org/10.1136/ thoraxjnl-2012-202592).

1 Department of Pulmonary Medicine, Zhongshan Hospital, Shanghai Medical College, Fudan University, Shanghai, China

${ }^{2}$ Department of Pulmonary Medicine, Huadong Hospital, Shanghai Medical College, Fudan University, Shanghai, China

${ }^{3}$ Department of Pulmonary Medicine, Fuyuan People's Hospital, Yunnan Province, China
\end{abstract}

\section{Correspondence to} Professor Jie-Ming Qu, Department of Pulmonary Medicine, Huadong Hospital Shanghai Medical College, Fudan University, 221 West Yan'an Road, Shanghai 200040, China; jmqu64@yahoo.com.cn

JZ and Y-LZ contributed equally to this paper.

Received 19 August 2012 Revised 2 December 2012 Accepted 18 December 2012 Published Online First 15 January 2013

\begin{abstract}
Background Patients with lung cancer are at high risk of venous thromboembolism (VTE), and VTE predicts a poor prognosis. Anticoagulation therefore might be beneficial for these patients. It is not clear whether anticoagulants could improve survival and other outcomes in patients with lung cancer with no indication for anticoagulation.
\end{abstract}

Methods We searched the Web of Science, Medline, EMBASE and Cochrane databases for relevant studies.

Two reviewers evaluated the studies and extracted data independently. The primary outcomes were 1-year survival and incidence of VTE. Pooled risk ratios (RR) were calculated using control as a reference group and significance was determined by the $Z$ test.

Results Nine eligible studies with 2185 participants were included. Anticoagulation showed significant improvement in survival at 1 year (RR $1.18,95 \% \mathrm{Cl}$ 1.06 to $1.32 ; p=0.004$ ) and at 2 years (RR 1.27, 95\% Cl 1.04 to $1.56 ; p=0.02$ ), but not at 6 months. Subgroup analysis showed a survival benefit for patients with small cell lung cancer (SCLC) and those with nonadvanced/limited cancer. The incidence of VTE ( $R R=0.55,95 \% \mathrm{Cl} 0.31$ to $0.97 ; p=0.04)$ and thromboembolic events (RR=0.48,95\% Cl 0.28 to 0.82 ; $\mathrm{p}=0.008$ ) was reduced with anticoagulation. Both vitamin $\mathrm{K}$ antagonist (VKA) and subcutaneous heparin increased the risk of haemorrhage, but heparin did not increase the incidence of major bleeding.

Conclusions Anticoagulation showed a survival benefit, especially for those with SCLC and prolonged life expectancy, and reduced the risk of VTE in lung cancer patients with no indication for anticoagulants. Subcutaneous heparin is superior to VKA because of a potentially smaller risk of major bleeding.

\section{INTRODUCTION}

It is well-known that malignancy is a common risk factor for venous thromboembolism (VTE). ${ }^{12}$ The incidence of VTE in patients with cancer has been reported to be increased by $>20$-fold compared with the general population, ${ }^{2}{ }^{3}$ and this risk seems to increase further by $20-30 \%$ in patients with advanced cancer who receive chemotherapy. ${ }^{45}$ Lung cancer is among the malignant diseases showing the highest incidence of VTE. ${ }^{16}$ Many patients with lung cancer have a history of smoking and thus are more likely to have comorbidities which may further increase the risk of thromboembolic events.

\section{Key messages}

What is the key question?

- Can anticoagulants improve survival and other outcomes in patients with lung cancer without indication for anticoagulation?

What is the bottom line?

- This meta-analysis revealed a long-term survival benefit in addition to reduced incidence of venous thromboembolism from anticoagulation treatment in patients with lung cancer who have no clinical indication for anticoagulants.

\section{Why read on?}

- Patients with small cell lung cancer or prolonged life expectancy might benefit most from adjunctive anticoagulation.

Activation of coagulation can predict a poor prognosis in patients with lung cancer. Previous studies showed that elevated plasma levels of thrombin-antithrombin complex and D-dimer were associated with increased mortality. ${ }^{7} 8$ The presence of VTE is also a significant independent predictor of death. ${ }^{3}$ Danish registry data indicate that 1-year survival in cancer patients with VTE is three times less than in those without VTE. ${ }^{9}$ A more recent study by Huang et $a l^{5}$ reported that lung cancer patients with VTE had a twofold shorter time to death.

Anticoagulants have potential antitumour effects by mechanisms of regulating growth, apoptosis and differentiation of neoplastic cells, inhibiting angiogenesis and modulating metastatic processes in addition to their antithrombotic effect. ${ }^{10}$ Some small-scale studies have suggested that concomitant treatment with heparin may improve the response rate to chemotherapy and prolong progression-free survival in patients with small cell lung cancer (SCLC). ${ }^{11-14}$ Putting these facts together, it is rational to consider using anticoagulants in patients with lung cancer to achieve a better outcome.

However, individual studies on the survival benefit and safety of anticoagulation in patients with lung cancer were of limited sample size and 
there has been a lack of consistency between various studies due to heterogeneity. We therefore performed a systematic literature review and meta-analysis to investigate the impact of anticoagulants on survival in patients with lung cancer. The impact on the incidence of thromboembolic events and adverse events such as bleeding was also evaluated.

\section{METHODS}

\section{Literature search}

A literature search was performed using the Web of Knowledge (1990-July 2012) via the library of Fudan University and Medline (1990-July 2012) by PubMed search engines, with the databases being last accessed on 15 August 2012. The Cochrane Central database and EMBASE were also searched for relevant studies published up to July 2012. No language restriction was imposed. The search strategies were as follows: (lung cancer OR SCLC OR non-SCLC (NSCLC)) AND (coagulant* OR anticoagulant* OR coagulation OR heparin OR warfarin OR low-molecular-weight heparin (LMWH) OR vitamin K antagonist (VKA) OR low molecular weight heparin). The reference lists of relevant publications were manually searched for additional studies. Ethical approval was not required for this meta-analysis.

\section{Study eligibility}

Two reviewers independently screened the abstracts of papers generated by the literature search, retrieved potentially relevant studies and determined study eligibility. Included studies had to be randomised controlled trials (RCTs) with at least two comparison groups (ie, anticoagulation treatment and controls) and survival data reported. Anticoagulation therapy could be oral VKA or heparin. In case of studies containing the same datasets as studies that had been published before, only the study with the largest sample size was included. Data published only in abstract form or from website materials were excluded because these studies had not been peer reviewed and their inclusion might introduce bias into the meta-analysis. Case reports, review articles and textbook chapters were also excluded from the analysis.

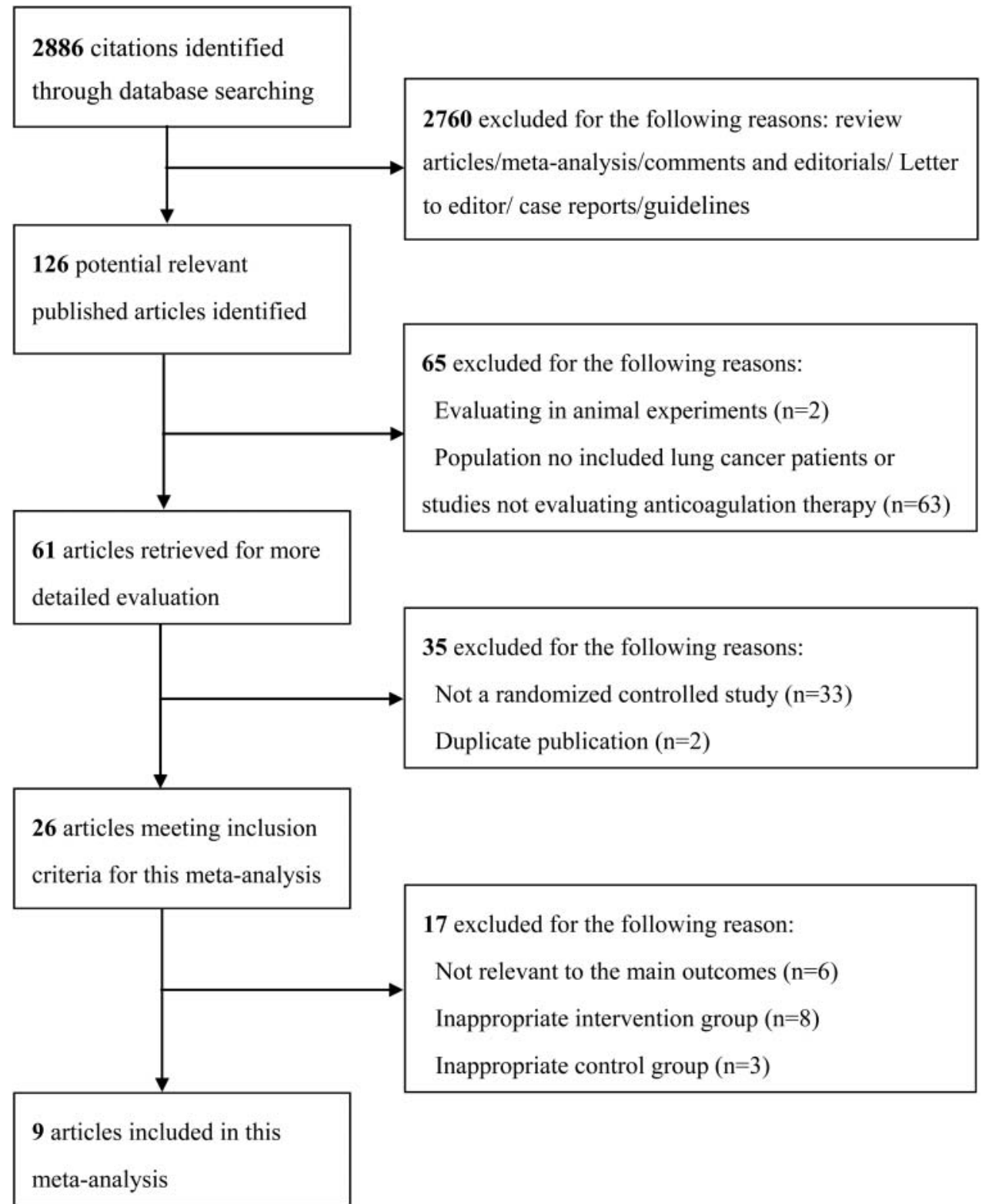

Figure 1 Flow of study selection. 
Table 1 Characteristics of studies included in the meta-analysis

\begin{tabular}{|c|c|c|c|c|}
\hline Study (year) & Population & Interventions & $\begin{array}{l}\text { No. of } \\
\text { patients }\end{array}$ & $\begin{array}{l}\text { Quality } \\
\text { score }\end{array}$ \\
\hline Agnelli (2009) & $\begin{array}{l}\text { Subjects extracted from the study with metastatic or } \\
\text { locally advanced lung cancer undergoing } \mathrm{CT}\end{array}$ & $\begin{array}{l}\text { Intervention: subcutaneous nadroparin } 3800 \text { IU anti-Xa once } \\
\text { daily. Control: placebo }\end{array}$ & $199 / 80$ & 5 \\
\hline Altinbas (2004) & Patients with SCLC undergoing chemotherapy & $\begin{array}{l}\text { Intervention: dalteparin } 5000 \mathrm{IU} \text { once daily during } 18 \text { weeks of } \\
\text { CT. Control: no intervention }\end{array}$ & $42 / 42$ & 2 \\
\hline $\begin{array}{l}\text { Altinbas-1 } \\
(2004)\end{array}$ & Subjects extracted from the study: limited SCLC & & $23 / 25$ & \\
\hline $\begin{array}{l}\text { Altinbas-2 } \\
(2004)\end{array}$ & Subjects extracted from the study: extensive SCLC & & $19 / 17$ & \\
\hline $\begin{array}{l}\text { Chahinian } \\
\text { (1989) }\end{array}$ & Patients with extensive SCLC undergoing $\mathrm{CT}$ & Intervention: VKA (PT 1.5-2). Control: no intervention & $103 / 85$ & 2 \\
\hline Haas (2012) & $\begin{array}{l}\text { Subjects extracted from the study with stage III/IV NSCLC } \\
\text { undergoing CT }\end{array}$ & $\begin{array}{l}\text { Intervention: certoparin } 3000 \text { IU subcutaneously once daily for } \\
6 \text { months. Control: placebo }\end{array}$ & $273 / 273$ & 5 \\
\hline Lebeau (1994) & Patients with limited or extensive SCLC undergoing CT & $\begin{array}{l}\text { Intervention: subcutaneous heparin for } 5 \text { weeks. Control: no } \\
\text { intervention }\end{array}$ & $138 / 139$ & 3 \\
\hline $\begin{array}{l}\text { Lebeau-1 } \\
\text { (1994) }\end{array}$ & Subjects extracted from the study: limited SCLC & & $64 / 57$ & \\
\hline $\begin{array}{l}\text { Lebeau-2 } \\
\text { (1994) }\end{array}$ & Subjects extracted from the study: extensive SCLC & & $74 / 82$ & \\
\hline Maurer (1997) & $\begin{array}{l}\text { Patients with limited SCLC undergoing CT and } \\
\text { radiotherapy; minimum life expectancy } 2 \text { months }\end{array}$ & $\begin{array}{l}\text { Intervention: VKA (PT 1.4-1.6) started with CT and continued } \\
\text { for } 3 \text { weeks after last cycle of CT. Control: no intervention }\end{array}$ & $178 / 169$ & 3 \\
\hline Stanford (1979) & Patients with stage III or more SCLC undergoing CT & Intervention: VKA following heparin. Control: no intervention & $12 / 12$ & 2 \\
\hline $\begin{array}{l}\text { van Doormaal } \\
\text { (2011) }\end{array}$ & $\begin{array}{l}\text { Subjects extracted from the study with stage IIIB NSCLC } \\
\text { receiving standard anticancer treatment }\end{array}$ & $\begin{array}{l}\text { Intervention: subcutaneous nadroparin for } 6 \text { weeks. Control: no } \\
\text { intervention }\end{array}$ & $81 / 88$ & 3 \\
\hline $\begin{array}{l}\text { Zacharski } \\
\text { (1984) }\end{array}$ & $\begin{array}{l}\text { Patients with different types of cancer undergoing CT; } \\
\text { minimum life expectancy of } 2 \text { months }\end{array}$ & Intervention: VKA (therapeutic range). Control: no intervention & & 3 \\
\hline $\begin{array}{l}\text { Zacharski-1 } \\
(1984)\end{array}$ & Subjects extracted from the study: advanced NSCLC & & $96 / 98$ & \\
\hline $\begin{array}{l}\text { Zacharski-2 } \\
(1984)\end{array}$ & Subjects extracted from the study: SCLC & & $25 / 25$ & \\
\hline $\begin{array}{l}\text { Zacharski-3 } \\
(1984)\end{array}$ & $\begin{array}{l}\text { Subjects extracted from the study: NSCLC following } \\
\text { potentially curative surgical resection or radiation therapy }\end{array}$ & & $21 / 20$ & \\
\hline
\end{tabular}

\section{Data extraction}

The full-text articles of all eligible studies were reviewed and data were extracted by the two authors independently. Any discrepancies were resolved by discussion with a third author to reach a final consensus. The extracted data included: (1) publication details; (2) sample size; (3) study methodology (eg, eligibility criteria, method of randomisation and blinding); (4) patient characteristics including pathological type and stage
Figure 2 Funnel plot for survival at 1 year showing no evidence of publication bias. This figure is only reproduced in colour in the online version.

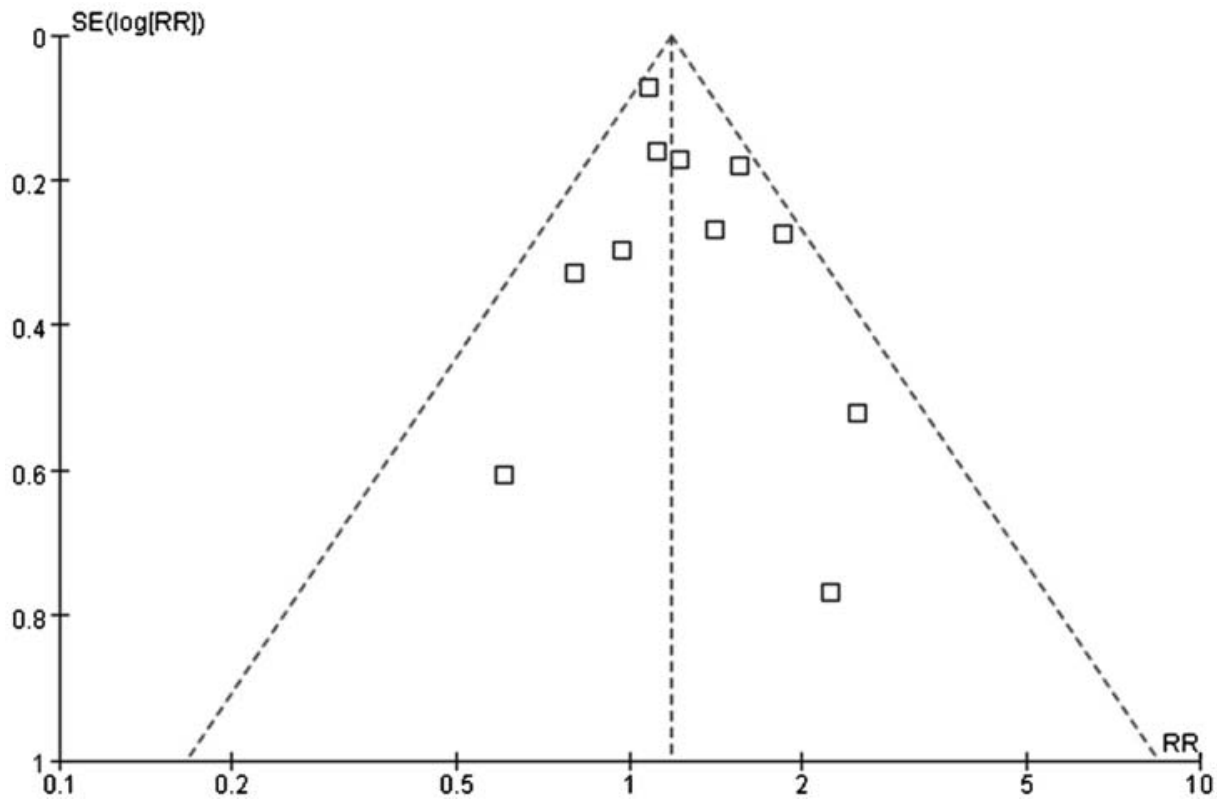




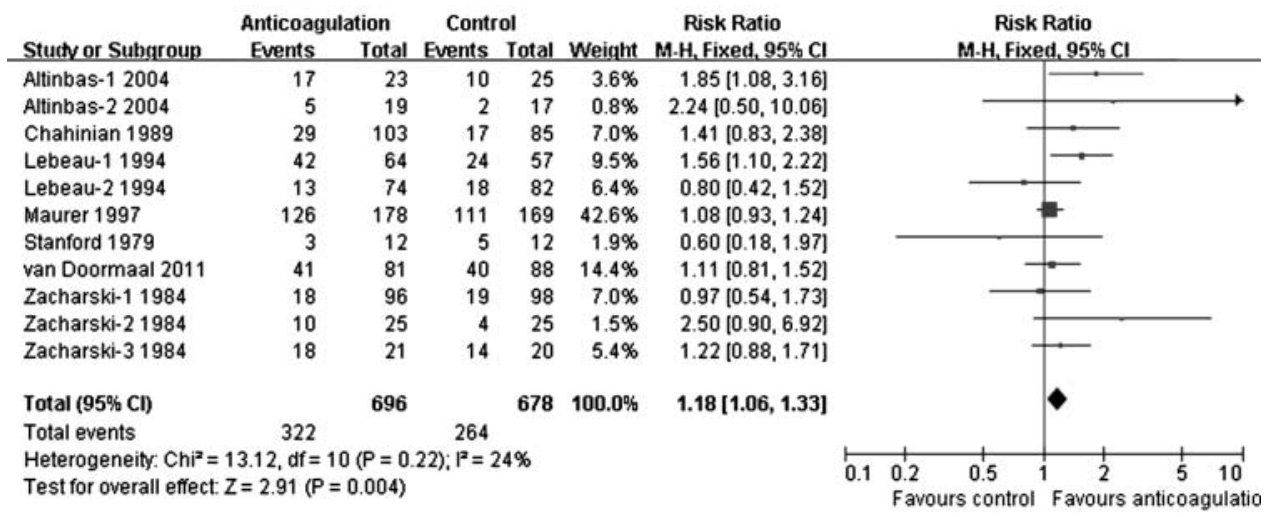

Figure 3 Forest plot showing the effect of anticoagulant treatment on survival at 1 year in patients with lung cancer. This figure is only reproduced in colour in the online version.

of lung cancer; (5) intervention (eg, type of anticoagulants, dose, route of administration and duration); and (6) clinical outcomes. The authors of the included studies were contacted for additional information if there were insufficient data for analysis.

The primary efficacy outcomes were survival rate at 1 year and incidence of VTE. Other outcomes also evaluated were: (1) symptomatic VTE and all reported thromboembolic events; (2) survival rate at 6 months and at 2 years; (3) adverse effects including haemorrhage events (major and minor bleeding) and thrombocytopenia. Survival data were collected at 6 months, 1 year and 2 years. When we could not obtain the number of survivors at the time points of interest from the paper or from the authors, two authors calculated these numbers independently and in duplicate from survival curves. We used the mean of the two estimates when they differed. VTE was defined as deep vein thrombosis of the lower or upper limbs, pulmonary embolism and visceral venous thrombosis. Thromboembolic events referred to VTE plus other thromboses such as stroke and peripheral thrombosis. ${ }^{15} 16$ Major bleeding was defined as The Cancer and Leukemia Group B (CALGB) toxicity grades 3-5 (grade 3, bleeding causing some functional disability and/ or requiring $<4$ units of blood; grade 4 , massive haemorrhage and/or profound functional disability and/or requiring $>4$ units of blood; grade 5, lethal haemorrhage). Overall haemorrhage events referred to major and minor bleeding. ${ }^{17}$

\section{Quality assessment}

We assessed the methodological quality of each trial using the Jadad score ${ }^{18}$ which incorporates randomisation, blinding and attrition to derive a score of $0-5$. Two reviewers independently appraised the quality of the included trials. Studies were considered to be of low quality if the Jadad score was $\leq 2$ and of high quality if the score was $\geq 3$.

\section{Statistical analysis}

An intervention meta-analysis was conducted using Review Manager Software 5.1.2 (Cochrane Collaboration, Oxford, UK). Pooled risk ratios (RRs) were calculated for all the outcomes. The $\chi^{2}$ test was used to evaluate the presence of statistically significant heterogeneity across the studies and the inconsistency index $\left(\mathrm{I}^{2}\right)$ was used to quantify the amount of heterogeneity. ${ }^{19}$ We predefined heterogeneity as low, moderate and high with $\mathrm{I}^{2}$ values of more than 25\%, 50\% and 75\%, respectively. Study-level data were pooled using a random effects model when $\mathrm{I}^{2}$ was $>50 \%$ or a fixed effects model when $\mathrm{I}^{2}$ was $<50 \%$. The significance of the pooled RR was determined by the $\mathrm{Z}$ test, along with $95 \%$ CIs. Publication bias was assessed by a funnel plot using 1-year survival as an endpoint. A p value of $<0.05$ was considered statistically significant.

Subgroup analyses were performed based on the type of anticoagulants (oral VKA vs subcutaneous heparin), histological

Table 2 Impact of additional anticoagulant therapy on survival rate at 1 year for patients with lung cancer

\begin{tabular}{|c|c|c|c|c|c|c|c|c|}
\hline \multirow[b]{2}{*}{ Variables } & \multirow{2}{*}{$\begin{array}{l}\text { Number of subjects } \\
\text { Anticoagulation/control } \\
\text { (number of studies, groups) }\end{array}$} & \multirow{2}{*}{$\begin{array}{l}\text { Number of events } \\
\text { Anticoagulation } \\
(\%) / \text { control (\%) }\end{array}$} & \multicolumn{3}{|c|}{ Anticoagulation vs control effect } & \multicolumn{3}{|c|}{ Heterogeneity } \\
\hline & & & RR $(95 \%$ Cl) & Z & $\mathrm{p}$ Value & $\chi^{2}$ & $\mathrm{p}$ Value & $I^{2}(\%)$ \\
\hline Total & $696 / 678(7,11)$ & $322(46.3) / 264(38.9)$ & 1.18 (1.06 to 1.32$)$ & 2.91 & 0.004 & 13.12 & 0.22 & 24 \\
\hline \multicolumn{9}{|l|}{ Anticoagulants } \\
\hline VKA & $435 / 409(4,6)$ & $204(46.9) / 170(41.6)$ & $1.13(0.99$ to 1.30$)$ & 1.80 & 0.07 & 5.02 & 0.41 & 0 \\
\hline Heparin & $261 / 269(3,5)$ & $118(45.2) / 94(34.9)$ & 1.28 (1.04 to 1.57$)$ & 2.37 & 0.02 & 6.34 & 0.18 & 37 \\
\hline \multicolumn{9}{|l|}{ Histological type } \\
\hline NSCLC & $102 / 108(2,3)$ & $77(38.9) / 73(35.4)$ & $1.10(0.87$ to 1.39$)$ & 0.78 & 0.44 & 0.60 & 0.74 & 0 \\
\hline SCLC & $498 / 472(6,8)$ & $245(49.2) / 191(40.5)$ & 1.21 (1.07 to 1.38$)$ & 2.94 & 0.003 & 12.75 & 0.08 & 45 \\
\hline \multicolumn{9}{|l|}{ Stage of lung cancer } \\
\hline Non-advanced/limited & $286 / 271(4,4)$ & $203(71.0) / 159(58.7)$ & 1.30 (1.03 to 1.65$)$ & 2.19 & 0.03 & 6.85 & 0.08 & 56 \\
\hline Advanced/extensive & $385 / 382(6,6)$ & $109(28.3) / 101(26.4)$ & 1.09 (0.87 to 1.36$)$ & 0.71 & 0.48 & 3.84 & 0.57 & 0 \\
\hline
\end{tabular}


Table 3 Impact of additional anticoagulant therapy on survival at 2 years for patients with lung cancer

\begin{tabular}{|c|c|c|c|c|c|c|c|c|}
\hline \multirow[b]{2}{*}{ Variables } & \multirow{2}{*}{$\begin{array}{l}\text { Number of subjects } \\
\text { Anticoagulation/control } \\
\text { (number of studies, groups) }\end{array}$} & \multirow{2}{*}{$\begin{array}{l}\text { Number of events } \\
\text { Anticoagulation (\%)/ } \\
\text { control (\%) }\end{array}$} & \multicolumn{3}{|c|}{ Anticoagulation vs control effect } & \multicolumn{3}{|c|}{ Heterogeneity } \\
\hline & & & RR $(95 \%$ Cl) & Z & $p$ Value & $\chi^{2}$ & $\mathrm{p}$ Value & $I^{2}(\%)$ \\
\hline Total & $684 / 666(6,10)$ & $148(21.6) / 113(17.0)$ & $1.27(1.04$ to 1.56$)$ & 2.34 & 0.02 & 4.15 & 0.90 & 0 \\
\hline \multicolumn{9}{|l|}{ Anticoagulation regimen } \\
\hline VKA & $423 / 397(3,5)$ & $100(23.6) / 77(19.4)$ & 1.23 (0.97 to 1.57$)$ & 1.71 & 0.09 & 0.68 & 0.95 & 0 \\
\hline Heparin & $261 / 269(3,5)$ & $48(18.4) / 36(13.4)$ & $1.36(0.93$ to 1.99$)$ & 1.60 & 0.11 & 3.62 & 0.46 & 0 \\
\hline \multicolumn{9}{|l|}{ Histological type } \\
\hline NSCLC & $198 / 206(2,3)$ & $44(22.2) / 37(18.0)$ & 1.24 (0.86 to 1.78$)$ & 1.14 & 0.25 & 0.63 & 0.73 & 0 \\
\hline SCLC & $486 / 460(5,7)$ & $104(21.4) / 76(16.5)$ & $1.29(1.01$ to 1.65$)$ & 2.05 & 0.04 & 3.60 & 0.73 & 0 \\
\hline \multicolumn{9}{|l|}{ Stage of lung cancer } \\
\hline Non-advanced/Limited & $286 / 271(4,4)$ & $107(37.4) / 76(28.0)$ & 1.33 (1.05 to 1.68$)$ & 2.38 & 0.02 & 3.42 & 0.33 & 12 \\
\hline Advanced/Extensive & $373 / 370(5,5)$ & $40(10.7) / 36(9.7)$ & 1.16 (0.77 to 1.73$)$ & 0.71 & 0.48 & 0.59 & 0.96 & 0 \\
\hline
\end{tabular}

type (NSCLC vs SCLC) and stage (non-advanced/limited vs advanced/extensive).

\section{RESULTS}

\section{Study description}

The initial literature search revealed a total of 2886 articles, from which 2760 were removed due to publishing type. After title and abstract screening, 65 citations were removed because they were not relevant to our study aim. Full-text screening of the remaining articles identified 26 potentially eligible citations. After evaluating these references, 17 articles were excluded for the following reasons: (1) not relevant to the main outcomes; (2) intervention was topical heparin or intraportal infusion of heparin, or the duration of anticoagulation therapy was $<5$ days or the comparison was between heparin and VKA; (3) concomitant treatments were different between intervention and control groups. In total, nine eligible RCTs of 2185 patients with lung cancer were included in the meta-analysis. ${ }^{11-15} 172021$ A flowchart of the evaluation of the studies is shown in figure 1 .

Five of the included studies recruited patients with lung cancer ${ }^{11-1420}$; the others were carried out in patients with different types of cancers. ${ }^{15-17} 21$ According to histological type and disease stage, a total of 13 groups were extracted from the nine studies. The primary outcome of the studies by Agnelli et $a l^{15}$ and Haas et $a l^{16}$ was thrombotic events and VTE events, respectively, and survival data at 1 year and 2 years were not available for these two studies. The average survival rate at 1 year was $42.6 \%$. Two studies of extensive SCLC in 1979 and 1989 reported low survival rates at 1 year of $33.3 \%$ and $24.5 \%$, respectively. ${ }^{14} 20$ The 1-year survival reported by Zacharski et $a l^{21}$ in 1984 was also low at 29.1\%. Four studies used VKA $^{13} \quad 14 \quad 2021$ and others used subcutaneous heparin, with unfractionated heparin in one study ${ }^{11}$ and LMWH in four studies. $^{12}{ }^{15-17}$ The characteristics of the included studies are summarised in table 1.

The average Jadad score of these studies was 3.1 (range 2-5). A funnel plot for the primary outcome indicated no evidence of publication bias (figure 2).

\section{Survival and subgroup analyses}

Survival at 1 year

The results from seven trials (11 groups, $n=1374$ patients) were available to examine the effects of anticoagulants on the survival rate at 1 year in patients with lung cancer. ${ }^{11-14} 172021$ No evidence of statistical heterogeneity was found for this outcome $\left(\mathrm{I}^{2}=24 \% ; \mathrm{p}=0.22\right)$. A pooled analysis showed that the use of anticoagulants was associated with a statistically significant improvement in 1-year survival (RR 1.18, 95\% CI 1.06 to 1.32 ; $\mathrm{p}=0.004$; figure 3).

For 1-year survival (table 2), heparin (RR 1.28, 95\% CI 1.04 to $1.57 ; \mathrm{p}=0.02$ ) showed a greater improvement than oral VKA (RR 1.13, 95\% CI 0.99 to $1.30 ; \mathrm{p}=0.07$ ); anticoagulation treatment showed efficacy in patients with SCLC (RR $1.21,95 \%$ CI 1.07 to $1.38 ; \mathrm{p}=0.003$ ) but not in those with NSCLC (RR $1.10,95 \%$ CI 0.87 to $1.39 ; \mathrm{p}=0.78$ ); and anticoagulants were found to have a beneficial effect in patients with non-advanced or limited lung cancer (RR 1.30, 95\% CI 1.03 to $1.65 ; p=0.03)$ but, in patients with advanced or extensive disease, the benefit was not statistically significant (RR $1.09,95 \%$ CI 0.87 to $1.36 ; p=0.48)$. The test for subgroup effect was not statistically significant for the three subgroup analyses.

Survival at 6 months

Eight studies including 1920 patients from 12 groups reported data on 6-month survival. ${ }^{11-14} \quad 16 \quad 17 \quad 20 \quad 21$ No statistically

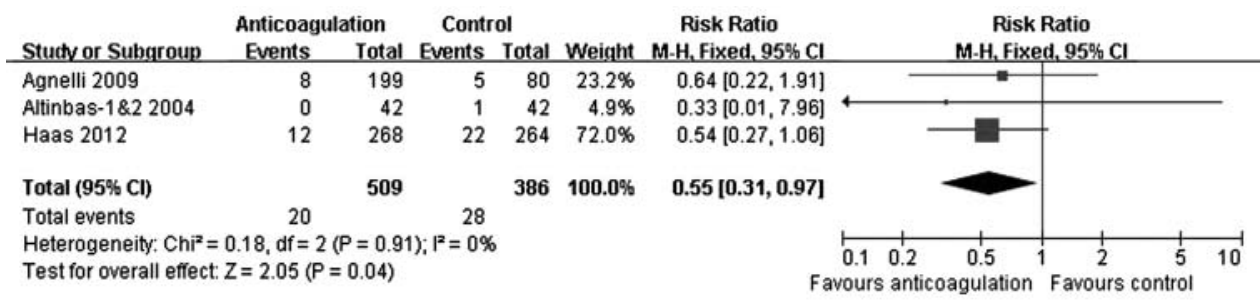

Figure 4 Forest plot showing the effect of anticoagulant treatment on the risk of overall venous thromboembolism. This figure is only reproduced in colour in the online version. 
Table 4 Impact of additional anticoagulant therapy on thromboembolic events for patients with lung cancer

\begin{tabular}{|c|c|c|c|c|c|c|c|c|}
\hline \multirow[b]{2}{*}{ Variables } & \multirow{2}{*}{$\begin{array}{l}\text { Number of subjects } \\
\text { Anticoagulation/control } \\
\text { (Number of studies) }\end{array}$} & \multirow{2}{*}{$\begin{array}{l}\text { Number of events } \\
\text { Anticoagulation (\%)/ } \\
\text { control (\%) }\end{array}$} & \multicolumn{3}{|c|}{ Anticoagulation vs Control effect } & \multicolumn{3}{|c|}{ Heterogeneity } \\
\hline & & & RR $(95 \% \mathrm{Cl})$ & Z & $\mathrm{p}$ Value & $\chi^{2}$ & $p$ Value & $I^{2}(\%)$ \\
\hline Overall VTE* & $509 / 386(3)$ & $20(3.9) / 28(7.3)$ & 0.55 (0.31 to 0.97$)$ & 2.05 & 0.04 & 0.18 & 0.91 & 0 \\
\hline Symptomatic VTE & 509/386 (3) & $15(2.9) / 20(5.2)$ & 0.56 (0.29 to 1.09$)$ & 1.70 & 0.09 & 0.26 & 0.88 & 0 \\
\hline Thromboembolic events & $509 / 386(3)$ & $20(3.9) / 32(8.3)$ & $0.48(0.28$ to 0.82$)$ & 2.65 & 0.008 & 0.06 & 0.97 & 0 \\
\hline
\end{tabular}

${ }^{*}$ Asymptomatic and symptomatic VTE. Thromboembolic events include deep vein thrombosis, pulmonary embolism, visceral venous thrombosis, stroke and peripheral thrombosis.

$\mathrm{RR}$, risk ratio; VTE, venous thromboembolism.

significant differences were found for the survival rate at 6 months between patients who received anticoagulants versus controls (RR 1.03 , 95\% CI 0.94 to $1.13 ; \mathrm{p}=0.51$ ). We found evidence of statistical heterogeneity for 6 -month survival $\left(\mathrm{I}^{2}=69 \% ; \mathrm{p}=0.0002\right.$; see online supplementary table $\mathrm{S} 1$ and supplementary figure $\mathrm{S} 1$ ).

\section{Survival at 2 years}

Ten groups from eight trials (1350 patients) contributed to the analysis of 2-year survival. ${ }^{11-14} 1721$ A meta-analysis found that anticoagulant administration had a beneficial effect on 2-year survival (RR 1.27, 95\% CI 1.04 to $1.56 ; \mathrm{p}=0.02$; table 3 and online supplementary figure S2). No evidence of statistical heterogeneity was found for this outcome $\left(\mathrm{I}^{2}=0 \% ; \mathrm{p}=0.90\right)$.

There was a significant beneficial effect in patients with SCLC (RR 1.29, 95\% CI 1.01 to $1.65 ; \mathrm{p}=0.04$, table 3 ). As for 1 -year survival, a significant benefit on 2 -year survival was seen in patients with non-advanced or limited lung cancer (RR 1.33, $95 \%$ CI 1.05 to $1.68 ; \mathrm{p}=0.02$ ) but not in those with advanced or extensive disease. The test for subgroup effect was not statistically significant for any of the three subgroup analyses.

\section{Thromboembolic events and subgroup analyses}

Only three RCTs provided information regarding thromboembolic events. ${ }^{12} 1516$ All of them used LMWH as anticoagulants. The meta-analysis showed that, compared with control, anticoagulant treatment was associated with a significant reduction in the risk of VTE (RR 0.55 , 95\% CI 0.31 to 0.97 ; $\mathrm{p}=0.04$; figure 4 ) and thromboembolic events (RR $0.48,95 \%$ CI 0.28 to $0.82 ; \mathrm{p}=0.008$; table 4$)$. Anticoagulation had a marginal effect on risk reduction for symptomatic VTE (RR 0.56, $95 \%$ CI 0.29 to $1.09 ; \mathrm{p}=0.09$ ).

\section{Haemorrhage events and subgroup analyses}

The main side effect of anticoagulants is bleeding. In our analysis of seven RCTs, ${ }^{11-16}{ }^{20}$ anticoagulation was associated with an apparent increase in the risk of overall haemorrhage events (RR 2.82, 95\% CI 2.14 to $3.74 ; \mathrm{p}<10^{-5}$; figure 5), major bleeding (RR 2.91, 95\% CI 1.43 to $5.90 ; \mathrm{p}=0.003$; figure 6) and minor bleeding (RR 2.78, 95\% CI 2.04 to $3.80 ; p=0.43$; see online supplement table S2) compared with control.

Despite the fact that the test for subgroup effect was not statistically significant for heparin versus oral VKA $(p=0.14$, figure 6$)$, it was noted that the increase in the risk of major bleeding for heparin was not statistically significant (RR $1.70,95 \%$ CI 0.66 to $4.40 ; \mathrm{p}=0.27)$ while VKA conferred a more significant effect (RR 5.14, 95\% CI 1.66 to $15.94 ; \mathrm{p}=0.005$ ).

\section{DISCUSSION}

Our meta-analysis revealed a survival benefit at 1 year and at 2 years from adjunctive anticoagulation in patients with lung cancer without indication for anticoagulants. The most recent analyses in this area were published by Akl et al in 2011.22 23 They investigated the impact of VKA and heparin on mortality in a mixed population of various cancers in two separate meta-analyses and found that heparin reduced mortality at

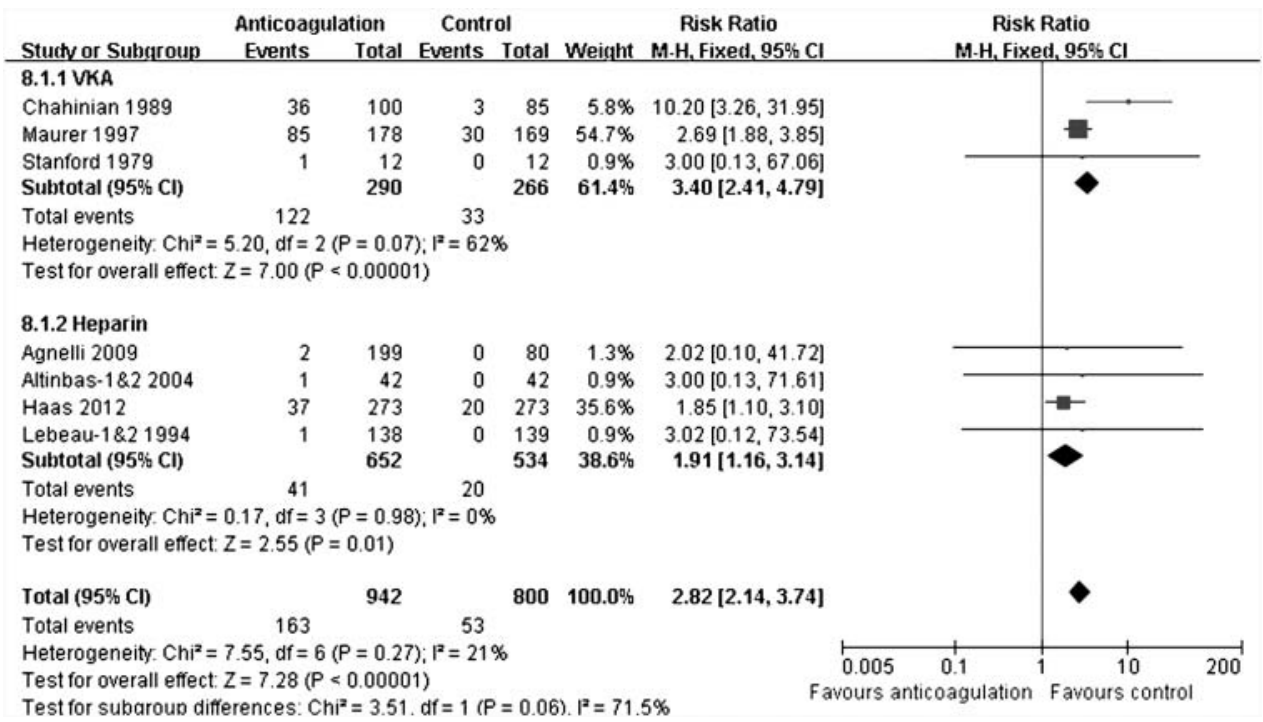

Figure 5 Forest plot showing the effect of anticoagulant treatment on the risk of overall haemorrhage events. This figure is only reproduced in colour in the online version. 


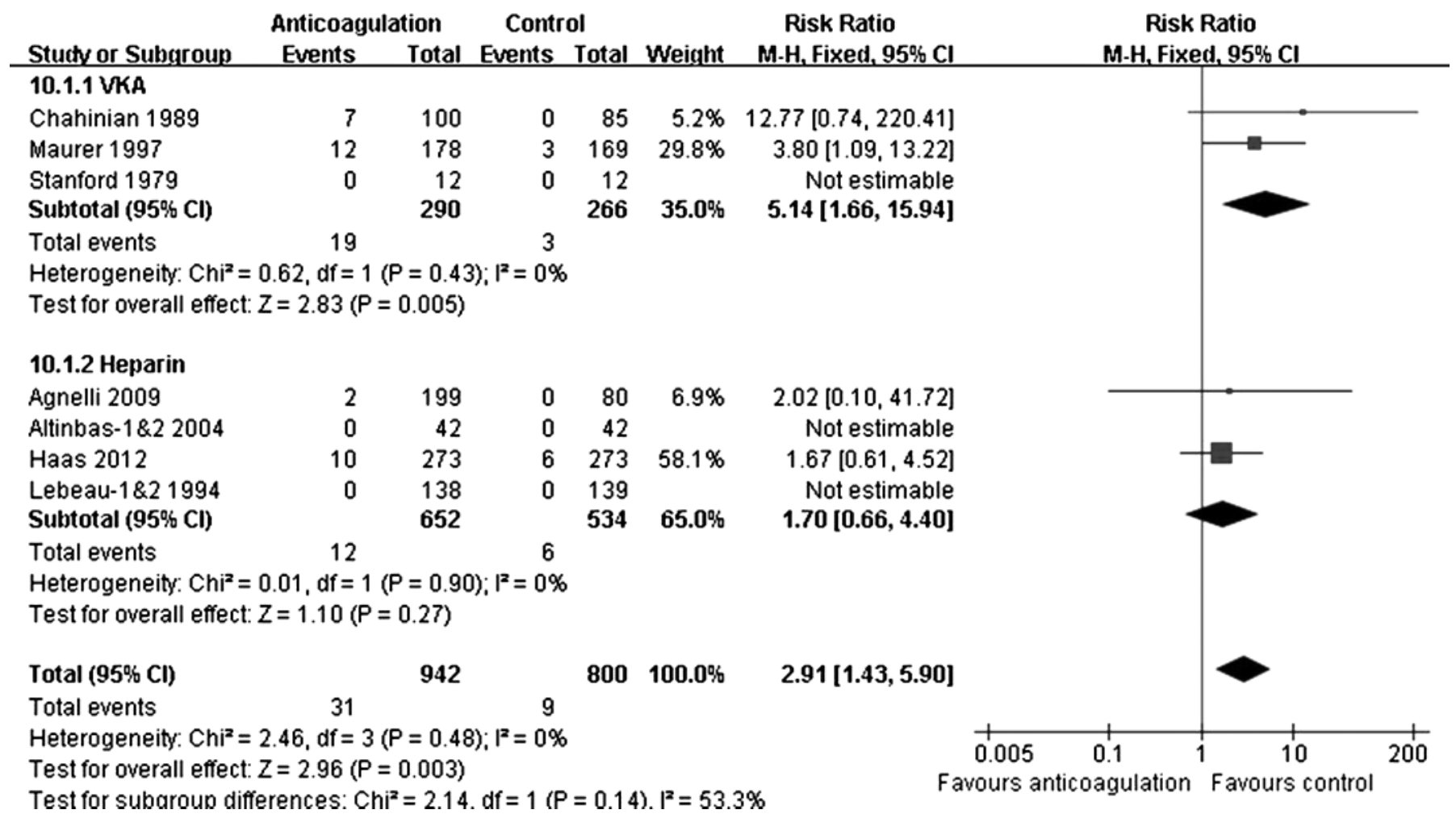

Figure 6 Forest plot showing the effect of anticoagulant treatment on the risk of major bleeding. This figure is only reproduced in colour in the online version. 
2 years but not at 1 year. ${ }^{22}$ No statistically significant benefit was found when using VKA. ${ }^{23}$ They performed a subgroup analysis of patients with SCLC versus other cancer types which suggested a reduction in mortality at 1 year with heparin in patients with SCLC but not in those with other cancers. ${ }^{22}$ Considering the especially high risk of VTE for lung cancer, we focused on patients with lung cancer and included participants from three additional studies for survival analysis. ${ }^{17} 2021$ Patients with NSCLC were also included in our analysis.

It is notable that the 1-year and 2-year survival benefit was seen in patients with lung cancer of non-advanced or limited stage but not in those with advanced or extensive cancer, and no statistically significant difference was found regarding survival at 6 months. In a RCT in patients with various types of cancer without underlying thrombosis, Kakkar et $a^{24}$ found that, in a subgroup of patients with a better prognosis, survival rates at 2 and 3 years were significantly improved for patients receiving LMWH versus placebo. In another similar study, Klerk et $a l^{25}$ reported that, in a subgroup of patients with a life expectancy of $\geq 6$ months, the HR of mortality for LWMH was 0.64 (95\% CI 0.45 to 0.90 ) compared with 0.88 (95\% CI 0.62 to 1.25 ) for patients with a shorter life expectancy. Together with these data, our findings suggest that anticoagulation might not produce an immediate survival benefit and it may be beneficial only in patients with prolonged life expectancy.

The underlying mechanisms of the increased survival from anticoagulation for lung cancer might be explained from two aspects. On one hand, our data-which are consistent with a previous analysis ${ }^{26}$ - suggest that adjunctive anticoagulation treatment can reduce the occurrence of VTE, which has been proved to be a risk factor for mortality. ${ }^{359}$ On the other hand, an accumulating number of in vitro and in vivo studies indicate that anticoagulants have an anticancer effect in non-antithrombotic pathways. ${ }^{27-30} \mathrm{In}$ clinical studies in patients with SCLC, the use of both VKA and heparin was found to improve significantly the response rate to chemotherapy and progression-free survival. ${ }^{11-14}$

Our data suggest that anticoagulation has a beneficial effect on 1-year and 2-year survival in patients with SCLC but not in those with NSCLC. Although subgroup analysis for the difference between SCLC and NSCLC was not statistically significant, it indicated a potential divergence in histological type. It should also be noted that only two included studies were eligible for the pooled analysis of NSCLC so the data might be insufficient to reveal a statistically significant potential benefit. Considering the fact that patients with NSCLC had a two-fold higher risk for VTE than those with SCLC, ${ }^{3}$ further studies are required for this cell type.

Anticoagulation may increase the incidence of bleeding, especially in patients receiving concomitant angiogenesis inhibitors and chemotherapy which might lead to thrombocytopenia. In our analysis we found that administration of anticoagulants can significantly increase the risk of major bleeding, minor bleeding and overall haemorrhage events. It has been shown in a previous study that factors including advanced age ( $\geq 65$ years), low platelet counts, a history of bleeding and the concomitant use of drugs such as angiogenesis inhibitors and high-dose systemic corticosteroids are also associated with a high bleeding rate. ${ }^{31}$ It may therefore be prudent to deliver anticoagulation therapy in patients with these risk factors.

The subgroup analysis, although not statistically significant, suggests that subcutaneous heparin might have a better effect on 1-year survival than oral VKA. Owing to the limited number of studies, we did not compare the effectiveness in reducing the risk of VTE between oral VKA and heparin, but previous studies have confirmed that LWMH may be superior in this respect. ${ }^{32}{ }^{33}$ Our data also suggest that oral VKA significantly increases the risk of major bleeding while subcutaneous heparin does not. These results are consistent with results from other studies. $22232631-33$ Furthermore, in the four trials included in the meta-analysis of adverse events of heparin there were no fatal bleeding events which had been judged to be related to heparin treatment. ${ }^{11} 121516$ Considering efficacy and safety, the potential superiority of subcutaneous heparin to oral VKA makes heparin the preferred choice of anticoagulation treatment in patients with lung cancer. Based on the available evidence, the most recent antithrombotic guideline of the American College of Chest Physicians has recommended against the use of VKA for longterm prophylaxis in patients with cancer, ${ }^{34}$ and future clinical trials should focus on the use of heparin rather than VKA.

Our study has several limitations. First, due to the differences in study design and protocol, the trials included in this meta-analysis had heterogeneity in two aspects: (1) subjects of each study had different histological types, different stages of disease and different anticancer treatments (chemotherapy or supportive therapy only); (2) a discrepancy in the anticoagulant agents, duration and dosage of anticoagulation treatment (table 1). However, it should be noted that all the included studies were RCTs comparing anticoagulants with controls and the characteristics of the participants in each study were comparable. In addition, data of the same histological type or disease stage were extracted and pooled analysed. Second, the quality of the included studies was not consistent. Only two of the nine included studies used placebo in the control group. ${ }^{15} 16$ The quality of trials can affect the direction and magnitude of treatment effects when undergoing a meta-analysis. Third, to elucidate which population can benefit from additional anticoagulation therapy and the most optimal regimen, three subgroup analyses were performed. However, due to the limited number of available eligible studies, no confirmed conclusions can be made at present.

\section{CONCLUSIONS}

The use of anticoagulants was found to have a survival benefit in patients with lung cancer without an indication for anticoagulation, especially those with SCLC or with non-advanced or limited disease. It was also associated with a decrease in thromboembolic events. The use of subcutaneous heparin was safe, showing no significant increase in the risk of major bleeding. Further trials are required to elucidate the efficacy and safety of anticoagulation therapy in diverse populations of lung cancer patients with various disease stages, performance status, life expectancy, cell types and concomitant anticancer drugs including new molecularly-targeted agents. The optimal agents, dose intensity, timing and duration of anticoagulants should also be investigated.

Acknowledgements The authors would like to thank Dr Lian Wu from University of Auckland, New Zealand for English editing.

Contributors IZ participated in the design of the study, carried out database search, performed article evaluation and statistical analysis and drafted the manuscript. Y-LZ carried out database search, article evaluation and data extraction. $\mathrm{K}$-XM participated in data extraction and statistical analysis. J-MQ conceived the idea, participated in study design and coordination and drafted/revised the manuscript. All authors read and approved the final manuscript.

Funding This research was sponsored by Shanghai Leading Talent Projects (No. 036, 2010).

Competing interests None.

Provenance and peer review Not commissioned; internally peer reviewed 


\section{REFERENCES}

1 Horsted F, West J, Grainge MJ. Risk of venous thromboembolism in patients with cancer: a systematic review and meta-analysis. PLoS Med 2012;9:e1001275.

2 Blom JW, Doggen CJ, Osanto S, et al. Malignancies, prothrombotic mutations, and the risk of venous thrombosis. JAMA 2005;293:715-22.

3 Chew HK, Davies AM, Wun T, et al. The incidence of venous thromboembolism among patients with primary lung cancer. J Thromb Haemost 2008;6:601-8.

4 Di Nisio M, Ferrante N, De Tursi M, et al. Incidental venous thromboembolism in ambulatory cancer patients receiving chemotherapy. Thromb Haemost 2010;104:1049-54

5 Huang $H$, Korn JR, Mallick R, et al. Incidence of venous thromboembolism among chemotherapy-treated patients with lung cancer and its association with mortality: a retrospective database study. J Thromb Thrombolysis 2012;34:446-56.

6 Tesselaar ME, Osanto S. Risk of venous thromboembolism in lung cancer. Curr Opin Pulm Med 2007;13:362-7.

7 Altiay G, Ciftci A, Demir M, et al. High plasma D-dimer level is associated with decreased survival in patients with lung cancer. Clin Oncol ( $R$ Coll Radiol) 2007;19:494-8.

8 Seitz R, Heidtmann HH, Wolf M, et al. Prognostic impact of an activation of coagulation in lung cancer. Ann Oncol 1997;8:781-4.

9 Sorensen HT, Mellemkjaer L, Olsen JH, et al. Prognosis of cancers associated with venous thromboembolism. N Engl J Med 2000;343:1846-50.

10 Robert F. The potential benefits of low-molecular-weight heparins in cancer patients. J Hematol Oncol 2010;3:3.

11 Lebeau B, Chastang C, Brechot JM, et al. Subcutaneous heparin treatment increases survival in small cell lung cancer. 'Petites Cellules' Group. Cancer 1994;74:38-45.

12 Altinbas M, Coskun HS, Er O, et al. A randomized clinical trial of combination chemotherapy with and without low-molecular-weight heparin in small cell lung cancer. J Thromb Haemost 2004;2:1266-71.

13 Maurer LH, Herndon JE II, Hollis DR, et al. Randomized trial of chemotherapy and radiation therapy with or without warfarin for limited-stage small-cell lung cancer: a Cancer and Leukemia Group B study. J Clin Oncol 1997;15:3378-87.

14 Chahinian AP, Propert KJ, Ware JH, et al. A randomized trial of anticoagulation with warfarin and of alternating chemotherapy in extensive small-cell lung cancer by the Cancer and Leukemia Group B. J Clin Oncol 1989;7:993-1002.

15 Agnelli G, Gussoni G, Bianchini C, et al. Nadroparin for the prevention of thromboembolic events in ambulatory patients with metastatic or locally advanced solid cancer receiving chemotherapy: a randomised, placebo-controlled, double-blind study. Lancet Oncol 2009;10:943-9.

16 Haas SK, Freund M, Heigener D, et al. Low-molecular-weight heparin versus placebo for the prevention of venous thromboembolism in metastatic breast cancer or stage III/IV lung cancer. Clin App/ Thromb Hemost 2012;18:159-65.

17 van Doormaal FF, Di Nisio M, Otten HM, et al. Randomized trial of the effect of the low molecular weight heparin nadroparin on survival in patients with cancer. J Clin Oncol 2011;29:2071-6.
18 Jadad ARMR, Carroll D, Jenkinson C, et al. Assessing the quality of reports of randomized clinical trials: is blinding necessary? Control Clin Trials 1996;17:1-12.

19 Higgins JPTS. Quantifying heterogeneity in a meta-analysis. Stat Med 2002;21:1539-8

20 Stanford CF. Anticoagulants in the treatment of small cell carcinoma of the bronchus. Thorax 1979:34:113-16.

21 Zacharski LR, Henderson WG, Rickles FR, et al. Effect of warfarin anticoagulation on survival in carcinoma of the lung, colon, head and neck, and prostate. Final report of VA Cooperative Study \#75. Cancer 1984;53:2046-52.

22 Akl EA, Gunukula S, Barba M, et al. Parenteral anticoagulation in patients with cancer who have no therapeutic or prophylactic indication for anticoagulation. Cochrane Database Syst Rev 2011;(1):CD006652.

23 Akl EA, Vasireddi SR, Gunukula S, et al. Oral anticoagulation in patients with cancer who have no therapeutic or prophylactic indication for anticoagulation. Cochrane Database Syst Rev 2011;(6):CD006466.

24 Kakkar AK, Levine MN, Kadziola Z, et al. Low molecular weight heparin, therapy with dalteparin, and survival in advanced cancer: the Fragmin Advanced Malignancy Outcome Study (FAMOUS). J Clin Oncol 2004;22:1944-8.

25 Klerk CP, Smorenburg SM, Otten HM, et al. The effect of low molecular weight heparin on survival in patients with advanced malignancy. J Clin Oncol 2005;23:2130-5

26 Verso M, Gussoni G, Agnelli G. Prevention of venous thromboembolism in patients with advanced lung cancer receiving chemotherapy: a combined analysis of the PROTECHT and TOPIC-2 studies. J Thromb Haemost 2010:8:1649-51.

27 Kakkar AK, Macbeth F. Antithrombotic therapy and survival in patients with malignant disease. Br J Cancer 2010;102(Suppl 1):S24-9.

28 Mousa SA. Anticoagulants in thrombosis and cancer: the missing link. Semin Thromb Hemost 2002;28:45-52.

29 Mousa SA, Mohamed S. Anti-angiogenic mechanisms and efficacy of the low molecular weight heparin, tinzaparin: anti-cancer efficacy. Oncol Rep 2004; $12: 683-8$

30 Hejna M, Raderer M, Zielinski CC. Inhibition of metastases by anticoagulants. J Nat Cancer Inst 1999;91:22-36.

31 Le Maitre A, Ding K, Shepherd FA, et al. Anticoagulation and bleeding: a pooled analysis of lung cancer trials of the NCIC Clinical Trials Group. J Thorac Oncol 2009;4:586-94.

32 Lee AY, Levine MN, Baker Rl, et al. Low-molecular-weight heparin versus a coumarin for the prevention of recurrent venous thromboembolism in patients with cancer. N Engl J Med 2003;349:146-53.

33 Akl EA, Barba M, Rohilla $S$, et al. Low-molecular-weight heparins are superior to vitamin $\mathrm{K}$ antagonists for the long term treatment of venous thromboembolism in patients with cancer: a Cochrane systematic review. J Exp Clin Cancer Res 2008;27:21.

34 Guyatt GH, Akl EA, Crowther M, et al. Executive summary: Antithrombotic Therapy and Prevention of Thrombosis, 9th ed: American College of Chest Physicians Evidence-Based Clinical Practice Guidelines. Chest 2012;141(2 Suppl):7S-47S. 